\title{
Commentary: Euthanasia in Europe: a critique of the Marty report
}

\section{G Widdershoven}

\section{Keown's critique of the Marty report is as flawed as the report it criticises}

E 2003, a report by the Council of Europe's social, health and family affairs committee appeared, questioning the council's opposition to the legislation of euthanasia. This report is known as the Marty report. The report contains several arguments in favour of legalisation of euthanasia. The first argument focuses on the gap between practice and law. Legalisation would bring existing practices of euthanasia out of the grey area, and make them more open to control. The second argument is that as long as euthanasia is legally forbidden, patients are forced to continue living in unbearable pain and suffering. In his critique of the Marty report, John Keown concludes that both arguments are invalid. ${ }^{1}$ He questions the presumed gap between practice and law, and criticises the conclusion that such a gap would imply that the law should be changed. He also argues that the notion of unbearable pain and suffering is highly problematic, and cannot serve as a justification for euthanasia. Although Keown's discussion shows thorough knowledge of the issue at hand, his conclusions are one sided and his dismissal of the position taken in the Marty report is too easy. In order to substantiate this, I will go into Keown's critique of the two arguments in the report.

\section{THE GAP BETWEEN PRACTICE AND LAW}

According to the Marty report, legalisation of euthanasia would bring existing practice into the open, and make decisions less arbitrary. Keown questions this argument in two ways. Firstly, he raises doubt as to whether the existing laws forbidding euthanasia are that often broken in practice. Several studies indicate that euthanasia is not very common in medical practice. If this is the case, the gap between law and practice is not as large as one might think. Keown rightly criticises some of the data used in the Marty report, and shows that the number of doctors involved in euthanasia is overestimated in the report. But even if the number of cases is not very large, it may be useful to reconsider the law. In The Netherlands, the number of euthanasia cases equals about $1.2 \%$ of the total number of deaths. The reason for the Dutch law to exempt physicians from prosecution (if they act in line with due care criteria) is not the number of cases, but the widely shared conviction that there is a distinction between the act of a physician who sees no other way out of a situation of unbearable suffering but to end the patient's life on the one in case of a discrepancy between law and practice, the gap should be narrowed by changing the law, rather than practice. He maintains that in many areas laws are broken, but that this does not mean they should be weakened or replaced. He mentions the example of possession of hard drugs. Even if laws on hard drugs are broken quite often, comparison is a bit too easy. In the case of euthanasia, well respected people (physicians) are breaking a law on moral grounds, and with the support of many people in society (first of all their patients). This is not to say that for this reason alone the law should be changed. It does show, however, that euthanasia is different from other acts that are currently illegal in many countries.

Keown suggests that legalisation of the practice of euthanasia would entail that problematic versions of this practice would be legalised. He mentions examples of euthanasia in cases of depression, or in cases in which palliative care would be a good option. If the answer to the gap between law and practice would simply be to make every existing practice legal, Keown's point would make sense. This is not, however, what the Marty report is about. The aim of the law is to make distinctions between proper cases of euthanasia and improper ones. According to the existing (Dutch and Belgian) laws, euthanasia is excluded in cases where depression influences the patient's abilhand, and murder on the other hand.

Secondly, Keown questions whether this is no reason to abolish them. This ity to make a well considered request. Palliative options have to be thoroughly investigated before euthanasia can be allowed. The laws in The Netherlands and in Belgium have put palliative care more explicitly on the agenda as alternatives for euthanasia. Thus, law may influence practice, in raising awareness of alternatives and making clear that euthanasia is only allowed if these alternatives are seriously considered. The law does not make all forms of actually practised euthanasia justified. On the contrary, it helps to distinguish between practices that are careful, and those that do not meet the criteria.

According to Keown, another objection to legalisation is that existing ways of regulating euthanasia focus on monitoring procedures, rather than on prohibition of practices that do not satisfy the criteria. The opposition proposed by Keown between monitoring on the one hand and prohibition on the other does not reflect the situation in The Netherlands and Belgium. In both countries, the monitoring procedures are not opposed to a prohibition of practices that do not meet the requirements; the former, both in law and in practice, presuppose the latter. Each case of euthanasia known not to be in line with the requirements (either through a judgment of the review committee or by other means) is examined by the public prosecutor. The penalty resulting from this depends on the seriousness of the breach of the requirements. Simply saying that the number of prosecutions, and the resulting penalties, are low, does not do justice to the legal procedures.

In his critique of legalisation of euthanasia as a solution to the gap between practice and law, Keown explicitly discusses the Dutch example. Although the Dutch system is certainly not perfect, the criticism is exaggerated. In contrast to Keown's claim that the bulk of cases are covered up by Dutch doctors, the most recent data show that around half of the cases were reported, and that general practitioners (the largest professional group performing euthanasia) reported in over $60 \%$. Moreover, this may be an underestimation of the percentage of cases reported, since it is possible that cases of terminal sedation (which in The Netherlandsand elsewhere-is regarded as normal medical practice, and therefore does not have to be reported) are probably being counted as euthanasia (because of the definitions used by the researchers). Keown also criticises the Dutch system for allowing physicians to make a report, saying that it is not likely they will disclose not having followed the rules. He does not mention that a report 
from the physician who has performed euthanasia has to be accompanied by the patient's file and by a report from an independent consulting physician. The file and the consultant's report contain important information for the monitoring process of the review committee. Finally, Keown criticises the Dutch system for the lack of a proper regulation of active ending of life without request. It is true that the law on euthanasia does not solve this problem; it does, however, enable a clear distinction to be made between cases of euthanasia and other forms of active ending of life. This does not mean that the Dutch exclude discussion about the non-voluntary ending of life by stating that this is not euthanasia, as Keown claims. In The Netherlands, discussion on this subject continues. Physicians and other participants have formulated proposals to deal with this matter. Although no definite legal arrangement has been made, the Dutch discussion is more open than elsewhere, and jurisprudence does give some guidelines.

\section{UNBEARABLE PAIN AND SUFFERING}

A second argument in the Marty report is that as long as euthanasia is illegal, some patients are condemned to continue living in a situation of unbearable pain and suffering. Keown counters this argument by questioning whether any suffering can be so great that people would be better off dead. According to him, patients who ask for euthanasia mistakenly think their life is no longer worth living, because they are in a state of depression, pain or loneliness. Physicians who positively respond to such a request, base their decision on "the arbitrary judgement (...) that they would be better off dead".

It may seriously be doubted whether this counterargument does justice to the motives of patients and doctors when considering euthanasia. Patients who make a request for euthanasia say they can no longer bear the suffering. When they declare that they cannot stand the situation any longer, this is not to say that their life has no worth. They may highly value life, but see no way to live it out any more. To suggest that they must suffer from depression, pain or loneliness, as Keown does, does no justice to the fact that many patients who have a realistic view of their situation, whose pain does not impair their judgment, and who care for others and are being cared for by them, may still want to have their lives ended because of the suffering they are currently experiencing, and the future they face.

A physician who decides to follow the patient's request does not act on the basis of a judgment about the worth of the patient's life, but on the basis of the judgment that the patient is suffering unbearably and without prospect of any improvement. This judgment is not necessarily arbitrary. It requires medical knowledge about the future course of the disease and understanding of the patient's experiences of the situation as being unbearable. The first criterion refers to medical expertise and scientific evidence. The latter acknowledges there are differences between patients, but that does not imply that such experiences are arbitrary. The fact that for each patient the limit may be different, does not mean that patients have no grounds for saying they cannot bear the situation any longer, or that physicians have no grounds for accepting this. In The Netherlands it is widely accepted that doctors are able to make judgments concerning suffering, knowing, as they do, the patient and his or her history. This is, however, also accepted in other countries, at least in so far as doctors are allowed to prescribe medicines to alleviate pain and suffering (even medicines that fully take away consciousness, in the case of terminal sedation).

In the Dutch context, judgments about unbearable pain and suffering are based upon open communication, and joint understanding, between physician and patient, a relevant context Keown does not mention. Therefore, in cases of euthanasia the judgment is never an act undertaken on the part of the patient or the doctor alone. This also implies that patients do not have the right to have their lives ended in the case of unbearable suffering. The cornerstone of the Dutch (and Belgian) law on euthanasia is the physician's conflict of duties, not patient rights. When Keown criticises the suggestion of the Marty report that people should have the right to have their lives ended in the case of unbearable suffering, his argument is not against, but in accordance with, Dutch and Belgian law.

In reaction to the statement of the Marty report that opponents of euthanasia compel patients to live out their life in unbearable suffering, Keown refers to the fact that one such opponent, Dame Cicely Saunders, devoted her life to the alleviation of pain and suffering. The importance of Cicely Saunders's work in the area of palliative care can hardly be overestimated. Yet, the development of palliative care has up to now not been able to prevent all kinds of suffering. As long as there are cases of suffering that cannot be resolved through palliative care, these patients will have to endure such suffering, if euthanasia is not allowed.

Judging that a patient suffers unbearably is never simple. Yet such judgments are inherent in medical practice, in The Netherlands as well as elsewhere in the world. The decision to end the patient's life in order to stop unbearable suffering is even more difficult. Yet such decisions are being made by doctors all over the world. The Dutch attempt to support doctors in this process by formulating rules and regulations may not be the best way to deal with these issues. Yet it is hard to follow Keown when he claims it is based upon fundamental misconceptions and automatically leads to immoral practices.

\section{CONCLUSION}

In his critique of the Marty report, Keown concludes that the report is flawed, because it overstates the arguments for the legalisation of euthanasia and downplays the arguments against this. Although Keown rightly criticises elements of the report, his critique is as flawed as the report it criticises, albeit in the opposite direction: arguments in favour of legalisation are downplayed, and arguments against are overstated. Whereas the Marty report is said to make a caricature of the opponents of euthanasia, Keown makes a caricature of its advocates, more specifically of the Dutch (and Belgian) practice of legalisation. This does not contribute to a genuine debate on the pros and cons of legalising euthanasia.

$J$ Med Ethics 2006;32:34-35.

doi: 10.1136/jme.2005.012146

Correspondence to: Guy Widdershoven, Department of Healthcare Ethics and Philosophy, Maastricht University, PO Box 616, 6200 MD Maastricht, The Netherlands; $g$. widdershoven@zw.unimaas.nl

Received 29 August 2005

Accepted for publication 7 September 2005

\section{REFERENCES}

1 Keown J. Euthanasia in Europe: a critique of the Marty report. J Med Ethics 2006;32:29-33. 